\title{
Multivariate Analysis and Traits Association in Hot Pepper (Capsicum annuum) Landraces of Ethiopia
}

\author{
Birhanu Habtie $^{1^{*}}$ and Tiegist Dejene ${ }^{2}$ \\ ${ }^{I}$ Ethiopian Institute of Agricultural Research (EIAR), Fogera Agricultural Research Center, Bahir Dar, P.O. \\ Box 1937, Ethiopia \\ ${ }^{2}$ Bahir Dar University, College of Agriculture and Environmental Sciences, Bahir Dar, P.O. Box 79, Ethiopia
}

*Corresponding Authors: Birhanu Habtie, Ethiopian Institute of Agricultural Research (EIAR),

Fogera Agricultural Research Center, Bahir Dar, P.O. Box 1937, Ethiopia

\begin{abstract}
A genetic diversity and traits association assessment in pepper is very important to generate information for future breeding programs. Hence, genetic variance study based on multivariate analysis and traits association assessment were done in thirty-six hot pepper landraces collected from Assosa region, Western part of Ethiopia. The experiment was laid in a simple lattice design at Assosa in Western Ethiopia and at Woramit in North Western Ethiopia. Data was collected for ten quantitative traits. Those genotypes were grouped into four clusters at $80.1 \%$ of similarity coefficient cutting edge using hierarchical complete linkage cluster analysis. The number of genotypes per cluster varied from six in cluster I and II to 13 in cluster IV confirmed the prevalence of genetic variation among genotypes for most of the traits considered. Further, the first five principal components explained $73.34 \%$ of the total variation prevalent within the accessions out of which $23.9 \%$ and $15.4 \%$ were explained by the first and second principal components, respectively. Correlation both at phenotypic and genotypic levels showed that dry fruit yield per plant was significantly and positively correlated with number of fruits per plant and fruit weight. Path coefficient analysis based on dry fruits yield per plant as a dependent variable also revealed that fruit weight and number of fruits per plant had the highest positive and direct effects. The highest positive indirect contribution to dry fruit yield per plant were observed by canopy diameter via number of fruits per plant at phenotypic level; and at genotypic level number of fruits per plant via canopy diameter and fruit diameter via fruit weight. Hence, number of fruits per plant, fruit diameter, fruit weight and canopy diameter can be used as indirect selection parameter for hot pepper dry fruit yield improvement.
\end{abstract}

Keywords: Capsicum annuum, Cluster pattern, Correlation, Principal Component.

\section{INTRODUCTION}

Pepper belongs to the genus Capsicum of the family Solanaceae (Berke, 2002). Pepper is originated from South and Central America and it spread to and grown widely in tropical and sub-tropical ecologies of the world (Ado, 1990; Berke, 2002). In Ethiopia, pepper was introduced by the Portuguese in the early $17^{\text {th }}$ century (Huffnaga, 1961). Ethiopia is so considered as a source of potantial local landraces of hot pepper which exposed to natural hybridization, disieases and pest reactions through long time serve as genetic resources to improve the yield and other related triaits. It is a national spice produced by small holder farmers and commercial growers for both local uses as well as for export in Ethiopia (Berhanu et al., 2011).

However, its productivity is very low with average national values of $6.29 \mathrm{t} / \mathrm{ha}$ and $1.83 \mathrm{t} / \mathrm{ha}$ green and red pepper yields, respectively (CSA, 2017). One of the main factors contributing to low yield of hot pepper is limitation of high yielding cultivars with desirable traits.

To cope with this problem improvement of hot pepper varieties using the local landraces is vital to increase the productivity of pepper. Hence, genetic diversity assessment is important initially to make selection and hybridizations which are frequently used for improving the variety (Dale and Schatz, 2002). In addition, association of characters among yield, its components, and other economic traits is important for making selection in breeding program and combining several desirable attributes (Johnson et al., 1955). Thus, the present investigation was conducted with the aim of 
evaluating thirty-six hot pepper genotypes to generate information for efficient selection, utilization, and adaptation in future pepper-breeding programs. Moreover, it is very important to assess the association of quantitative traits which is useful in evolving selection criteria for improvement in pepper.

\section{Materials AND Methods}

\subsection{Experimental Materials}

The field experiment was carried out at Assosa Agricultural Research Center (AARC) and Woramit horticultural research site of Adet Agricultural Research Center. AARC has an altitude of $1580 \mathrm{~m}$.a.s with annual rain fall $1275 \mathrm{~mm}$. The minimum and maximum temperature is $14^{\circ} \mathrm{c}$ and $39^{\circ} \mathrm{c}$, respectively (Birhanu et.al, 2017). Where as altitude of Woramit Horticultural Research Sub-Center is 1800 m.a.s.l. The mean annual temperature range is $6.2^{\circ} \mathrm{c}-29.5^{\circ} \mathrm{c}$ and the area receives $800-1250 \mathrm{~mm}$ annual rain fall (Habtamu Tegen et al., 2014).

Thirty-six local landraces of hot pepper and one improved variety as a check which obtained from AARC were included in the experiment. List of the experimental materials are given in Table 1.

Table1. List of hot pepper genotypes and their codes

\begin{tabular}{|l|l|l|l|l|l|}
\hline Entry \# & Code & Accession Name & Entry \# & Code & Accession Name \\
\hline 1 & 1 & AS 52 & 19 & 19 & AS 37 \\
\hline 2 & 2 & AS 110 & 20 & 20 & AS 31 \\
\hline 3 & 3 & AS 56 & 21 & 21 & AS 42 \\
\hline 4 & 4 & AS 104-2 & 22 & 22 & AS 57 \\
\hline 5 & 5 & AS 94 & 23 & 23 & AS 23 \\
\hline 6 & 6 & AS 138-2 & 24 & 24 & AS 142 \\
\hline 7 & 7 & AS 39 & 25 & 25 & AS 43 \\
\hline 8 & 8 & AS 105 & 26 & 26 & AS 47 \\
\hline 9 & 9 & AS 40 & 27 & 27 & AS 58-2 \\
\hline 10 & 10 & AS 119 & 28 & 28 & AS 75 \\
\hline 11 & 11 & AS 139 & 29 & 29 & AS 63 \\
\hline 12 & 12 & AS 58-1 & 30 & 30 & AS 5 \\
\hline 13 & 13 & AS 54 & 31 & 31 & AS 15 \\
\hline 14 & 14 & AS 60 & 32 & 32 & Melka Zala (check) \\
\hline 15 & 15 & AS 24 & 33 & 33 & AS 87 \\
\hline 16 & 16 & AS 78 & 34 & 34 & AS 17 \\
\hline 17 & 17 & AS 59 & 35 & 35 & AS 8 \\
\hline 18 & 18 & AS 50 & 36 & 36 & AS 138-1 \\
\hline
\end{tabular}

\subsection{Experimental Design and Field Management}

It was laid out in a $6 \times 6$ simple lattice design in a plot size of $2.4 \mathrm{~m} \mathrm{X} 3 \mathrm{~m}$. The seedling was transplanted when it attained $15-20 \mathrm{~cm}$ height with the spacing of $0.3 \mathrm{~m}$ between plants and $0.6 \mathrm{~m}$ between ridges under rain fed condition of 2016/2017. Spacing between incomplete block and replications were at the distance of $0.6 \mathrm{~m}$ and $0.75 \mathrm{~m}$ apart, respectively. Fertilizers at the rate of 200 $\mathrm{kg} / \mathrm{ha}$ DAP and $100 \mathrm{~kg} / \mathrm{ha}$ Urea was used and all other recommended field managements of pepper was applied. Urea was applied in two rounds, the first half during transplanting as a side dressing and the second half after 15 days from transplanting. While all amount of DAP applied at the time of transplanting.

\subsection{Data Collection}

Data collection and surveillance (heritable agronomic traits) for all traits were based on descriptor from IPGRI (1996). The data was recorded on plant basis: plant height, canopy diameter, fruit diameter, number of branches per plant, fruit length, number of fruits per plant and fruit weight. While days to 50\% flowering, days to first harvest and dry fruit yield were recorded on plot basis. 


\subsection{Statistical Analysis}

Analysis of phenotypic and genotypic correlations was computed using the method described by Singh and Chaundray (1996). The Pearson correlation test were applied for phenotypic and genotypic correlation coefficients respectively using SAS (SAS, 2008) version 9.1 Software. A measure of direct and indirect effects of each character on yield was estimated using a standardized partial regression coefficient known as path coefficient analysis, as suggested by Dewey and Lu (1959). Thus, correlation coefficient of different traits with dry fruit yield was partitioned into direct and indirect effects using Microsoft Excel program.

Complete linkage hierarchical cluster analysis approach was also used to examine the assembling pattern of the 36 hot pepper genotypes based on their similarity with respect to the corresponding means of all the traits studied. For all traits studied, the data were standardized to have a mean of zero and a variance of one prior to Squared Euclidian distance. The dendrogram was constructed based on the Complete Linkage and Euclidean Distance used as a measure of dissimilarity (the distance) technique using the Minitab (version 14) software package (Minitab Inc., 1998). Genetic divergence between clusters was determined using the generalized Mahalanobis's $\mathrm{D}^{2}$ statistics (Mahalanobis, 1936). The $D^{2}$ analysis was based on the mean values of all traits by using SAS software program. In order to identify pattern of morphological variation of genotypes, principal component analysis was performed using JMP version 13.1 Software (SAS, 2013).

\section{RESULTS AND DiSCUSSION}

\subsection{Correlation}

Analysis of phenotypic and genotypic correlation values of ten quantitative traits combined over two locations is presented in figure 1.

\section{Genotypic Correlation Coefficient $\left(\mathbf{r}_{\mathrm{g}}\right)$}

As illustrated in figure 1 dry fruit yield per plant was significantly $(\mathrm{p}<0.01)$ and positively correlated with number of fruit per plant $(\mathrm{r}=0.28)$ and highly significant with fruit weight $(\mathrm{r}=0.52)$. As a result these characters were the major components for pepper of dry fruit yield per plant .On the other hand, it had highly significant and negative correlation with days to first harvest $(\mathrm{r}=-0.70)$, fruit length $(\mathrm{r}=$ $-0.58)$ and canopy diameter $(\mathrm{r}=-0.30)$. Fruit weight showed highly significant and positive correlation with fruit length $(\mathrm{r}=0.39)$ and number of fruits per plant $(\mathrm{r}=0.37)$; and highly significantly and negatively correlation with number of primary branches $(r=-0.36)$. Negative and significant correlation was also observed between days to first harvest and fruit length $(r=-0.27)$. Both plant height $(\mathrm{r}=0.28)$ and canopy diameter $(\mathrm{r}=0.25)$ showed significant and positive correlation with days to $50 \%$ flowering, but days to $50 \%$ flowering had highly significant and positive correlation with number of fruits per plant $(\mathrm{r}=0.58)$. It was also significantly and negatively correlation with fruit length $(\mathrm{r}=-0.345)$. Fruit diameter was correlated highly significant and negative with plant height $(\mathrm{r}=$ $-0.34)$ and number of fruits per plant $(\mathrm{r}=-0.44)$, although it was highly significant and positively correlated with number of primary branches per plant $(r=0.32)$. It had also significant and negative correlation with fruit length $(\mathrm{r}=-0.60)$. Fruit length had significant and positive correlation with plant height $(\mathrm{r}=0.30)$ and highly significant and negative correlation with number of branches per plant $(\mathrm{r}$ $=-0.40$ ). There was significant and positive correlation between number of fruits per plant and plant height $(r=0.27)$; and between number of fruits per plant and canopy diameter $(r=0.27)$.

\section{Phenotypic Correlation Coefficient $\left(\mathbf{r}_{\mathrm{p}}\right)$}

In phenotypic correlation analysis, plant height showed highly significant $(\mathrm{P}<0.01)$ and negative correlation with fruit diameter $(\mathrm{r}=-0.336)$ (Figure 1). It also had significant and positive correlation with canopy diameter $(r=0.241)$. Canopy diameter showed highly significant and positive correlation with number of fruits per plant $(\mathrm{r}=0.418)$. Fruit diameter was found significantly and positive correlation with fruit weight $(\mathrm{r}=0.341)$. Dry fruit yield per plant was correlated significant and positive with fruit weight $(r=0.298)$ and number of fruits per plant $(r=0.0254)$.

The current finding was in line with Berhanu et al (2011) outputs in hot pepper showed that there was a positive and significance in both phenotype and genotype correlation of fruit yield per plant with fruit length and fruit weight. Razzaq et al (2016) also reported that fruit width and fruit length with 
dry fruit yield; and plant height with fruit length had a significant positive correlation which was in agreement with the current finding.

Figure1. Heat map of estimate of correlation coefficients at genotypic (above diagonal) and phenotypic levels (below diagonal) for ten quantitative traits in hot peppers based on combined data over two locations.

\begin{tabular}{lllllllllllll}
\hline & PH & CD & NPB & NF & FL & FD & DFPF & DFH & FW & DFY & $r$ \\
PH & 1.00 & $0.06^{\mathrm{NS}}$ & $0.15^{\mathrm{NS}}$ & $0.27^{*}$ & $0.29^{*}$ & $-0.39^{* *}$ & $0.28^{*}$ & $0.05^{\mathrm{NS}}$ & $-0.05^{\mathrm{NS}}$ & $0.02^{\mathrm{NS}}$ & 1.00 \\
CD & $0.24^{*}$ & 1.00 & $-0.22^{\mathrm{NS}}$ & $0.27^{*}$ & $0.19^{\mathrm{NS}}$ & $-0.14^{\mathrm{NS}}$ & $0.25^{*}$ & $0.20^{\mathrm{NS}}$ & $-0.06^{\mathrm{NS}}$ & $-0.30^{* *}$ & \\
NPB & $0.14^{\mathrm{NS}}$ & $0.06^{\mathrm{NS}}$ & 1.00 & $-0.16^{\mathrm{NS}}$ & $-0.40^{* *}$ & $0.32^{* *}$ & $-0.21^{\mathrm{NS}}$ & $0.24^{\mathrm{NS}}$ & $-0.36^{* *}$ & $0.02^{\mathrm{NS}}$ & 0.60 \\
NF & $0.33^{* *}$ & $0.42^{* *}$ & $0.03^{\mathrm{NS}}$ & 1.00 & $-0.18^{\mathrm{NS}}$ & $-0.44^{* *}$ & $0.58^{* *}$ & $-0.1^{\mathrm{NS}}$ & $0.37^{* *}$ & $0.28^{*}$ & \\
FL & $0.13^{\mathrm{NS}}$ & $0.10^{\mathrm{NS}}$ & $-0.13^{\mathrm{NS}}$ & $-0.15^{\mathrm{NS}}$ & 1.00 & $-0.59^{*}$ & $-0.35^{*}$ & $-0.27^{*}$ & $0.39^{* *}$ & $-0.58^{* *}$ & 0.20 \\
FD & $-0.34^{* *}$ & $-0.08^{\mathrm{NS}}$ & $0.20^{\mathrm{NS}}$ & $-0.21^{\mathrm{NS}}$ & $-0.23^{\mathrm{NS}}$ & 1.00 & $0.10^{\mathrm{NS}}$ & $-0.18^{\mathrm{NS}}$ & $-0.09^{\mathrm{NS}}$ & $0.14^{\mathrm{NS}}$ & 1 \\
DFPF & $0.12^{\mathrm{NS}}$ & $-0.06^{\mathrm{NS}}$ & $-0.13^{\mathrm{NS}}$ & $0.02^{\mathrm{NS}}$ & $-0.03^{\mathrm{NS}}$ & $-0.07^{\mathrm{NS}}$ & 1.00 & $0.15^{\mathrm{NS}}$ & $0.19^{\mathrm{NS}}$ & $0.18^{\mathrm{NS}}$ & -0.20 \\
DFH & $0.11^{\mathrm{NS}}$ & $0.10^{\mathrm{NS}}$ & $0.07^{\mathrm{NS}}$ & $-0.14^{\mathrm{NS}}$ & $0.18^{\mathrm{NS}}$ & $-0.21^{\mathrm{NS}}$ & $0.12^{\mathrm{NS}}$ & 1.00 & $0.18^{\mathrm{NS}}$ & $-0.70^{* *}$ & -0.60 \\
FW & $-0.16^{\mathrm{NS}}$ & $-0.07^{\mathrm{NS}}$ & $0.04^{\mathrm{NS}}$ & $-0.21^{\mathrm{NS}}$ & $0.11^{\mathrm{NS}}$ & $0.34^{* *}$ & $-0.04^{\mathrm{NS}}$ & $-0.17^{\mathrm{NS}}$ & 1.00 & $0.52^{* *}$ & -1.00 \\
DFY & $0.08^{\mathrm{NS}}$ & $-0.13^{\mathrm{NS}}$ & $-0.01^{\mathrm{NS}}$ & $0.25^{*}$ & $-0.10^{\mathrm{NS}}$ & $0.17^{\mathrm{NS}}$ & $-0.10^{\mathrm{NS}}$ & $-0.23^{\mathrm{NS}}$ & $0.30^{*}$ & 1.00 & \\
\hline
\end{tabular}

Where, *,**, Significant at 0.05 and 0.01 , probability levels, respectively. NS $=$ non- significant at 0.05 and 0.01 probability level, $\mathrm{PH}=$ plant height, $\mathrm{CD}=$ canopy diameter, $\mathrm{NPB}=$ number of primary branches per plant, $\mathrm{NF}=$ number of fruits per plant, $\mathrm{FL}=$ fruit length, $\mathrm{FD}=$ fruit diameter, $\mathrm{DFPF}=$ days to $50 \%$ flowering, $\mathrm{DFH}=$ days to $1^{\text {st }}$ harvesting, $\mathrm{FW}=$ Average fruit weight and $\mathrm{DFY}=$ dry fruit yield per plant.

\subsection{Path Coefficient Analysis}

Traits of canopy diameter, number of fruits per plant, fruit length, fruit diameter and average fruit weight have significant and direct correlation with dry fruit yield per plant. Accordingly, both the phenotypic and genotypic correlations were partitioned into direct and indirect effect using dry fruit yield as a dependent variable (Dewey and Lu, 1959).

\section{Phenotypic path coefficient analysis}

Number of fruits per plant $(\mathrm{rp}=0.254)$ and fruit weight $(0.298)$ showed significant $(\mathrm{p}<0.01)$ and positive phenotypic association with dry fruit yield per plant. Number of fruits per plant and fruit weight had major positive direct effects on fruit yield per plant followed by fruit diameter but their values are small with relative to residual effect. Similarly, its value is small with respect to residual effect, canopy diameter revealed higher negative direct contribution to dry fruit yield per plant. Hence, these characters could be considered as main component in selection program to increase the yield of dry fruit yield in hot peppers. (Table 2).

The highest positive phenotypic indirect contribution to dry fruit yield per plant was observed by canopy diameter via number of fruits per plant $(0.1783)$ even if its value is not much to the residual one. Traits like fruit diameter via canopy diameter, fruit weight via canopy diameter, fruit length via number of fruits per plant and fruit diameter, fruit diameter via fruit weight; and fruit weight via fruit diameter had positive phenotypic effects; however, its impact were negligible (Table2).

Table2. Estimate of direct (bold diagonal) and indirect (off diagonal) at phenotypic level of nine traits on dry fruit yield per plant in 36 hot pepper genotypes based on the combined data over two locations.

\begin{tabular}{|l|l|l|l|l|l|l|l|l|l|l|}
\hline Traits & PH & CD & NPB & NF & FL & FD & DFPF & DFH & FW & $\mathbf{r}_{\mathbf{p}}$ \\
\hline PH & $\mathbf{0 . 1 6 8}$ & -0.074 & -0.013 & 0.139 & -0.004 & -0.058 & -0.016 & -0.004 & -0.053 & 0.084 \\
\hline CD & 0.040 & $\mathbf{- 0 . 3 0 7}$ & -0.005 & 0.178 & -0.003 & -0.014 & 0.008 & -0.004 & -0.021 & -0.13 \\
\hline NPB & 0.024 & -0.018 & $\mathbf{- 0 . 0 9 3}$ & 0.011 & 0.004 & 0.034 & 0.017 & -0.003 & 0.013 & -0.01 \\
\hline NF & 0.054 & -0.128 & -0.002 & $\mathbf{0 . 4 2 7}$ & 0.005 & -0.035 & -0.003 & 0.005 & -0.068 & $0.254^{*}$ \\
\hline FL & 0.022 & -0.029 & 0.012 & -0.065 & $\mathbf{- 0 . 0 3 0}$ & -0.039 & 0.004 & -0.007 & 0.036 & -0.09 \\
\hline FD & -0.056 & 0.025 & -0.018 & -0.088 & 0.007 & $\mathbf{0 . 1 7 2}$ & 0.009 & 0.008 & 0.112 & 0.171 \\
\hline DFPF & 0.021 & 0.019 & 0.012 & 0.009 & 0.001 & -0.012 & $\mathbf{- 0 . 1 3 2}$ & -0.005 & -0.013 & -0.10 \\
\hline DFH & 0.018 & -0.029 & -0.006 & -0.060 & -0.005 & -0.035 & -0.016 & $\mathbf{- 0 . 0 3 8}$ & -0.056 & -0.23 \\
\hline FW & -0.027 & 0.020 & -0.004 & -0.088 & -0.003 & 0.059 & 0.005 & 0.007 & $\mathbf{0 . 3 3 0}$ & $0.298^{*}$ \\
\hline
\end{tabular}


Residual are 0.68474. Where, $\mathrm{PH}=$ plant height, $\mathrm{CD}=$ canopy diameter, $\mathrm{NPB}=$ number of primary branches per plant, $\mathrm{NF}=$ number of fruits per plant, $\mathrm{FL}=$ fruit length, $\mathrm{FD}=$ fruit diameter, $\mathrm{DFPF}=$ days to $50 \%$ flowering, $\mathrm{DFH}=$ days to $1^{\text {st }}$ harvesting, $\mathrm{FW}=$ Average fruit weight.

\section{Genotypic path coefficient analysis}

Significant $(\mathrm{P}<0.01)$ and positive genotypic association to dry fruit yield per plant was found in both number of fruit $\left(r_{g}=0.278\right)$ and fruit weight $\left(r_{g}=0.523\right)$. On the other hand, canopy diameter ($0.302)$, fruit length $(-0.575)$ and fruit diameter $(-0.699)$ indicated significant $(\mathrm{P}<0.01)$ and negative genotypic association to dry fruit yield per plant. The result of path coefficient analysis revealed that the highest positive direct cause to dry fruit yield per plant was exhibited by days to $50 \%$ flowering followed by number of fruits per plant and fruit diameter. As a result days to 50\% flowering, numbers of fruits per plant and fruit diameter are important traits during selecting germplasm lines for desirable of dry fruit yield per plant in hot peppers.

Number of fruits per plant via canopy diameter and fruit diameter via fruit weight revealed the highest positive indirect effect on dry fruit yield per plant. However, the indirect effect of canopy diameter through fruit diameter and fruit weight; and fruit length through number of fruits per plant and fruit diameter as well as fruit weight through fruit diameter on dry fruit yield per plant were positive but these are negligible. In addition, important negative and indirect effect on dry fruit yield per plant were observed mainly by number fruits per plant through fruit diameter and fruit weight; and by fruit diameter through number of fruits per plant and fruit length.(Table 4). Similar results had obtained by Shimeles et al (2016) which were the positive direct effect on fruit yield per plant by fruit diameter, flowering period and number of fruits per plant but days to fruiting had negative direct effect on yield with the residual effect values of 0.27 .

Table4. Estimate of direct (bold diagonal) and indirect (off-diagonal) at genotypic level of nine traits on dry fruit yield per plant in 36 hot pepper genotypes based on the combined data over two locations.

\begin{tabular}{|l|l|l|l|l|l|l|l|l|l|l|}
\hline Traits & PH & CD & NPB & NF & FL & FD & DFPF & DFH & FW & $\mathbf{r}_{\mathbf{g}}$ \\
\hline PH & $\mathbf{5 . 6 7}$ & -0.09 & -0.88 & 2.95 & -0.59 & -4.09 & -3.26 & 0.37 & -0.05 & 0.02 \\
\hline CD & 0.358 & $\mathbf{- 1 . 4 6}$ & 1.319 & 2.984 & -0.38 & -1.462 & -2.901 & 1.406 & -0.16 & $-0.3^{* *}$ \\
\hline NPB & 0.824 & 0.317 & $\mathbf{- 6 . 0 9}$ & -1.797 & 0.839 & 3.363 & 2.449 & 0.175 & -0.06 & 0.015 \\
\hline NF & 1.507 & -0.39 & 0.984 & $\mathbf{1 1 . 1 2 5}$ & 0.377 & -4.648 & -6.857 & -1.41 & -0.40 & $0.28^{*}$ \\
\hline FL & 1.634 & -0.27 & 2.458 & -2.019 & $\mathbf{- 2 . 0 8}$ & -6.241 & 4.063 & 1.462 & 0.418 & $-0.58^{* *}$ \\
\hline FD & -2.21 & 0.203 & -1.94 & -4.910 & 1.232 & $\mathbf{1 0 . 5 3}$ & -1.226 & -1.98 & 0.445 & 0.141 \\
\hline DFPF & 1.572 & -0.3 & 1.267 & 6.481 & 0.718 & 1.097 & $\mathbf{1 1 . 7 7}$ & 1.282 & -0.11 & 0.18 \\
\hline DFH & 0.290 & -0.29 & -0.15 & -2.171 & -0.42 & -2.890 & -2.089 & $\mathbf{- 7 . 2 3}$ & -0.21 & $-0.69^{* *}$ \\
\hline FW & -0.26 & 0.203 & 0.349 & -3.993 & -0.76 & 4.124 & 1.074 & -1.34 & $\mathbf{1 . 1 3 6}$ & $0.523^{* *}$ \\
\hline
\end{tabular}

Residual are $\mathbf{0 . 3 8 6 1 4}$. Where, $\mathrm{PH}=$ plant height, $\mathrm{CD}=$ canopy diameter, $\mathrm{NPB}=$ number of primary branches per plant, $\mathrm{NF}=$ number of fruits per plant, $\mathrm{FL}=$ fruit length, $\mathrm{FD}=$ fruit diameter, $\mathrm{DFPF}=$ days to $50 \%$ flowering, $\mathrm{DFH}=$ days to $1^{\text {st }}$ harvesting, $\mathrm{FW}=$ Average fruit weight

\subsection{Cluster Analysis}

Hierarical Complete linkage cluster analysis using standardized Mahalanobis $\left(\mathrm{D}^{2}\right)$ statics has been used to classify genotypes into different groups. The 36 hot pepper genotypes were grouped into four at $80.1 \%$ of similarity coefficient cutting edge using a combined data over two locations.

Figure2 Dendrogram of 36 genotypes into two ways clustering which express the contribution of traits to which cluster

The number of genotypes varies from six in cluster I \& II to 13 in cluster IV implies that prevalence of genetic variation among genotypes for most of the traits under consideration. (Table5).

Table5. The distribution of accessions on six clusters based $D^{2}$ analysis for 36 hot pepper genotypes tested at Assosa and Woramit.

\begin{tabular}{|l|l|l|l|}
\hline Clusters & $\begin{array}{l}\text { No of } \\
\text { Genotypes. }\end{array}$ & Genotypes Name & $\begin{array}{l}\text { Genotypes } \\
\text { distribution in \% }\end{array}$ \\
\hline I & 6 & AS52, AS42, AS23,AS142, AS43, AS58-2 & 16.7 \\
\hline II & 6 & AS56, AS105, AS54, AS60, AS31, AS15 & 16.7 \\
\hline
\end{tabular}




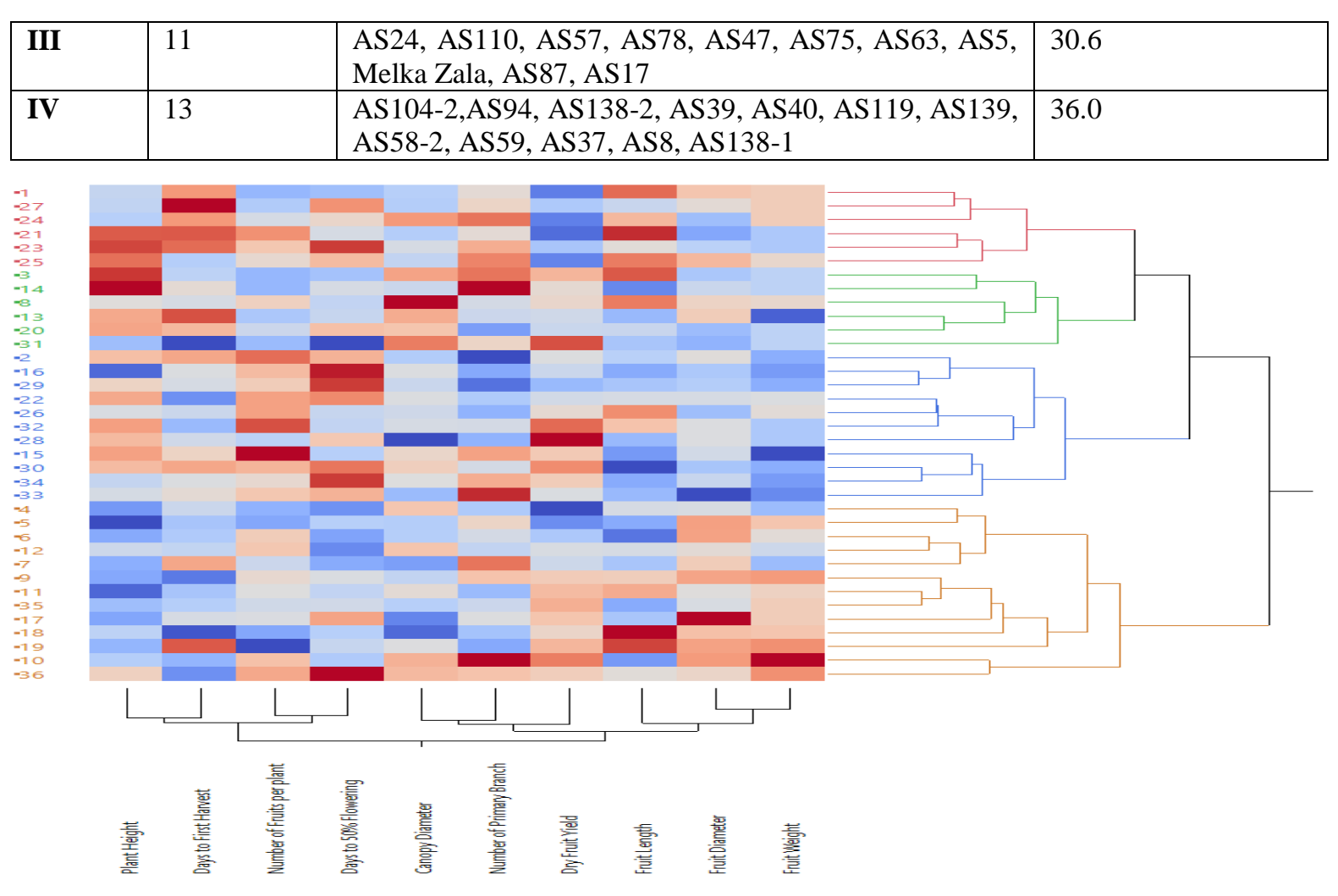

From the cluster mean analysis result, the highest fruit weight was recorded in cluster I (3.18) and the lowest by cluster II (2.32). The highest mean values for days to $50 \%$ flowering (56.82) and days to first harvest (124.1) revealed in cluster III and cluster II, respectively. However, the lowest mean values for days to 50\% flowering (53.61) and days to first harvest (119.2) were exhibited by cluster IV and cluster I, respectively. This indicated that cluster III had late flowering genotypes whereas cluster IV had early flowering genotypes. Cluster II comprised the latest maturing genotypes with relatively the highest plant height (66.19) where as cluster I had widest canopy (62.88) with early maturing (119.2) genotypes. Cluster III also represent genotypes consisting greater number of fruits per plant (14.34) with highest dry fruit yield per plant (Table 6).

Table6. Cluster mean values for the six clusters based on the combined data over location of ten quantitative traits in hot peppers

\begin{tabular}{|l|l|l|l|l|}
\hline Characters & Cluster I & Cluster II & Cluster III & Cluster IV \\
\hline PH & 63.54 & 66.19 & 63.76 & 58.55 \\
\hline CD & 62.88 & 56.03 & 54.16 & 54.30 \\
\hline NPB & 5.700 & 5.220 & 4.980 & 4.860 \\
\hline NF & 13.80 & 14.28 & 14.34 & 13.39 \\
\hline FL & 11.44 & 11.20 & 10.80 & 11.42 \\
\hline FD & 30.68 & 29.38 & 29.88 & 32.46 \\
\hline DFPF & 53.62 & 56.81 & 56.82 & 53.61 \\
\hline DFH & 119.2 & 124.1 & 121.7 & 121.5 \\
\hline FW & 3.180 & 2.320 & 2.340 & 2.820 \\
\hline DFY & 51.56 & 42.97 & 53.60 & 44.63 \\
\hline
\end{tabular}

Where, $\mathrm{PH}=$ plant height, $\mathrm{CD}=$ canopy diameter, $\mathrm{NPB}=$ number of primary branches per plant, $\mathrm{NF}=$ number of fruits per plant, $\mathrm{FL}=$ fruit length, $\mathrm{FD}=$ fruit diameter, $\mathrm{DFPF}=$ days to $50 \%$ flowering, $\mathrm{DFH}=$ days to $1^{\text {st }}$ harvesting, $\mathrm{FW}=$ Average fruit weight and DFY $=$ dry fruit yield per plant.

Considering the inter-cluster distance or squared Euclidean distances, the highest dissimilarity were shown between cluster I and II (12.86) followed by I and IV (12.49), II and III (11.35). This result revealed the presence of considerable genetic variability among included genotypes. Cluster I showed the maximum genetic distance from II and so, it is possible to get the genotypes from cluster I and II that offer parental lines for hybrid variety development program in the future. (Table7). 
Table7. Average intra (bold diagonal) and inter cluster distance (below diagonal) among 36 genotypes based on the combined data over location of the ten quantitative traits in hot peppers.

\begin{tabular}{|l|l|l|l|l|}
\hline Clusters & I & II & III & IV \\
\hline I & $\mathbf{9 . 9 7}$ & & & \\
\hline II & 12.86 & $\mathbf{9 . 6 3}$ & & \\
\hline III & 9.97 & 11.35 & $\mathbf{9 . 9 7}$ & \\
\hline IV & 12.49 & 9.63 & 11.23 & $\mathbf{9 . 6 3}$ \\
\hline
\end{tabular}

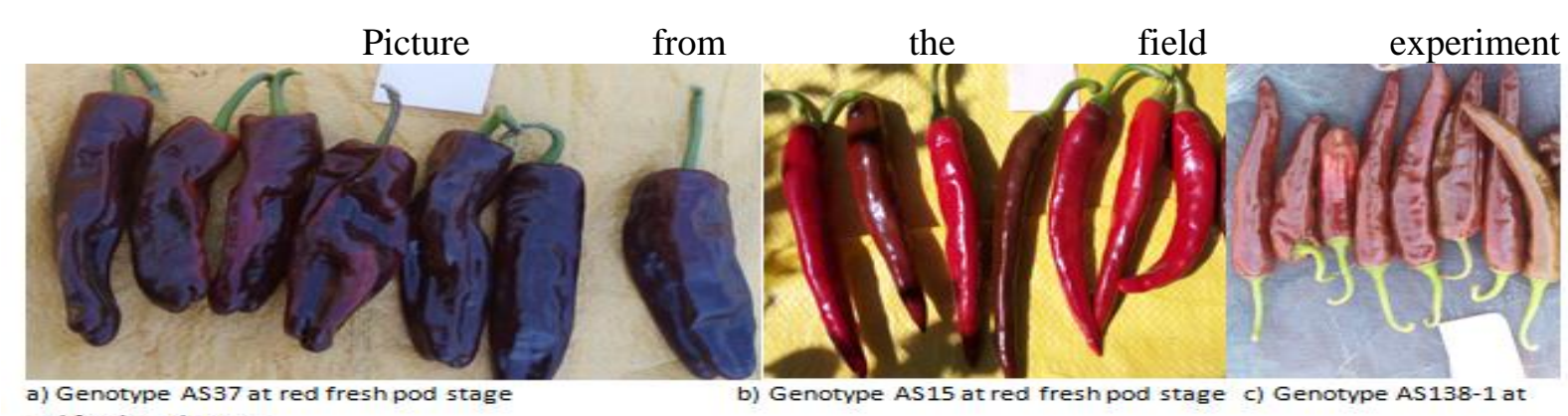
red fresh pod stage

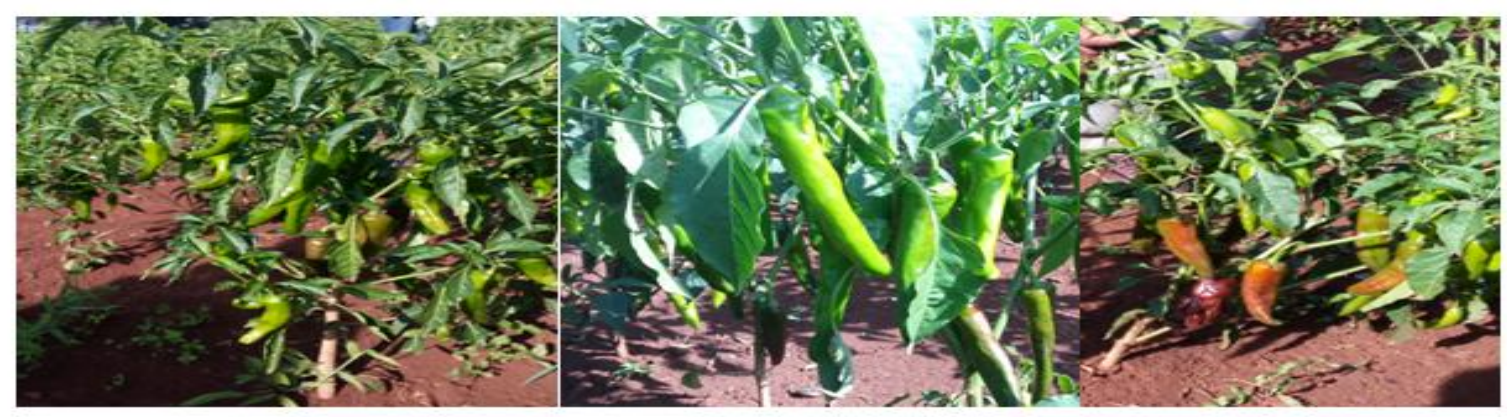

d) Genotype AS37 at vegetative stage e) Genotype AS15at vegetative stage f) GenotypeAS138-1 at vegetative stage

\subsection{Principal component analysis}

Principal component axes (PCA), with their respective eigenvectors and variance of 36 genotypes for 10 quantitative traits are explained in Table 8. The first five principal components were displayed eigenvalues $>1.0$, together accounted $73.34 \%$ of total variation among accessions for 10 quantitative traits considered. These principal components Prin1, Prin2, Prin3, Prin4 and Prin5 had eigenvalues of $2.38,1.53,1.42,1.06$ and 1.02 , respectively. In the first Prin, which explained $23.38 \%$ of total variation, the most important traits that contribute to the genetic variation were days to first harvest, days to 50\% flowering, number of fruits per plant and plant height through positive loading and fruit weight and diameter through negative loading. In the second Prin, this accounted $15.3 \%$ of total variation, the predominant traits that contribute to the genetic variation were number of fruits per plant and dry fruit yield per plant through positive loading, and fruit length and days to first harvest through negative loading. Previous researcher such as Bozokalfa et al (2009) and Occhiuto et al (2014) used PCA to know the genetic variability and to characterized and evaluated hot pepper accessions. Nsabiyera et al (2012) also reported important contribution of the first five Prins in total variability while studying different quantitative traits.

Table8. Eigenvalues, total variance, cumulative variance and eigenvectors for 10 quantitative traits in 36 hot pepper genotypes from the combined data over two locations

\begin{tabular}{|l|l|l|l|l|l|l|l|l|l|l|}
\hline Traits & Prin1 & Prin2 & Prin3 & Prin4 & Prin5 & Prin6 & Prin7 & Prin8 & Prin9 & Prin10 \\
\hline Plant Height & 0.43 & -0.08 & 0.27 & 0.29 & 0.31 & -0.42 & 0.06 & 0.28 & -0.43 & -0.35 \\
\hline Canopy Diameter & 0.04 & 0.00 & 0.63 & -0.18 & 0.01 & 0.56 & 0.43 & 0.11 & -0.22 & 0.15 \\
\hline $\begin{array}{l}\text { Number of Primary } \\
\text { Branch }\end{array}$ & -0.01 & 0.03 & 0.46 & 0.65 & -0.40 & -0.11 & -0.24 & -0.17 & 0.16 & 0.29 \\
\hline $\begin{array}{l}\text { Number of Fruits per } \\
\text { plant }\end{array}$ & 0.35 & 0.38 & -0.03 & 0.12 & 0.28 & 0.40 & -0.38 & 0.42 & 0.39 & -0.01 \\
\hline Fruit Length & -0.15 & -0.48 & 0.20 & -0.06 & 0.66 & -0.13 & -0.15 & -0.07 & 0.23 & 0.40 \\
\hline Fruit Diameter & -0.47 & 0.02 & -0.27 & 0.30 & 0.00 & 0.03 & 0.08 & 0.63 & -0.32 & 0.35 \\
\hline
\end{tabular}

International Journal of Research Studies in Agricultural Sciences (IJRSAS)

Page $\mid 48$ 


\begin{tabular}{|l|l|l|l|l|l|l|l|l|l|l|}
\hline $\begin{array}{l}\text { Days to 50\% } \\
\text { Flowering }\end{array}$ & 0.33 & 0.10 & -0.40 & 0.41 & 0.27 & 0.25 & 0.30 & -0.45 & -0.22 & 0.29 \\
\hline Days to First Harvest & 0.29 & -0.50 & -0.17 & 0.14 & -0.25 & -0.01 & 0.48 & 0.30 & 0.49 & -0.03 \\
\hline Fruit Weight & -0.50 & 0.01 & 0.06 & 0.40 & 0.27 & 0.22 & 0.19 & -0.13 & 0.22 & -0.60 \\
\hline Dry Fruit Yield & -0.08 & 0.60 & 0.12 & -0.08 & 0.16 & -0.46 & 0.48 & 0.03 & 0.32 & 0.20 \\
\hline Eigenvalues & $\mathbf{2 . 3 4}$ & $\mathbf{1 . 5 3}$ & $\mathbf{1 . 4 2}$ & $\mathbf{1 . 0 6}$ & $\mathbf{1 . 0 2}$ & $\mathbf{0 . 8 1}$ & $\mathbf{0 . 7 1}$ & $\mathbf{0 . 5 6}$ & $\mathbf{0 . 3 8}$ & $\mathbf{0 . 2 0}$ \\
\hline \% of total variances & $\mathbf{2 3 . 3 8}$ & $\mathbf{1 5 . 3 2}$ & $\mathbf{1 4 . 1 5}$ & $\mathbf{1 0 . 5 5}$ & $\mathbf{1 0 . 1 7}$ & $\mathbf{8 . 0 7}$ & $\mathbf{7 . 0 7}$ & $\mathbf{6 . 6 3}$ & $\mathbf{3 . 7 9}$ & $\mathbf{1 . 9 6}$ \\
\hline \% of cum variances & $\mathbf{2 3 . 3 8}$ & $\mathbf{3 8 . 6 1}$ & $\mathbf{5 2 . 7 7}$ & $\mathbf{6 3 . 3 2}$ & $\mathbf{7 3 . 4 9}$ & $\mathbf{8 1 . 5 7}$ & $\mathbf{8 8 . 6 1}$ & $\mathbf{9 4 . 2 5}$ & $\mathbf{9 8 . 0 2}$ & $\mathbf{1 0 0 . 0}$ \\
\hline
\end{tabular}

A principal component bi-plot in figure 3 showed that the variables and the genotypes are overlapping and distributed on the plot quadrants as vectors showing genetic variability among hot pepper genotypes of quantitative traits. Each quadrant in principal component bi-plot also indicated the association of genotypes with the different traits. A bi-plot also observed the distance of each parameter from the origin with respect to Prin1 and Prin2 indicated the contribution of these parameters in the variation of the genotypes considered in this study. So that dry fruit yield per pant, fruit weight, days to first harvest and number of fruits per plant as a whole contributes maximum towards variability regards to Prin1 and Prin2. Nsabiyera et al (2012) explained that plant height, maturity date, number of fruits per plant and canopy diameter had greater contributed traits to genetic variability of their tested hot pepper germplasms with regard to the first and the second principal components.

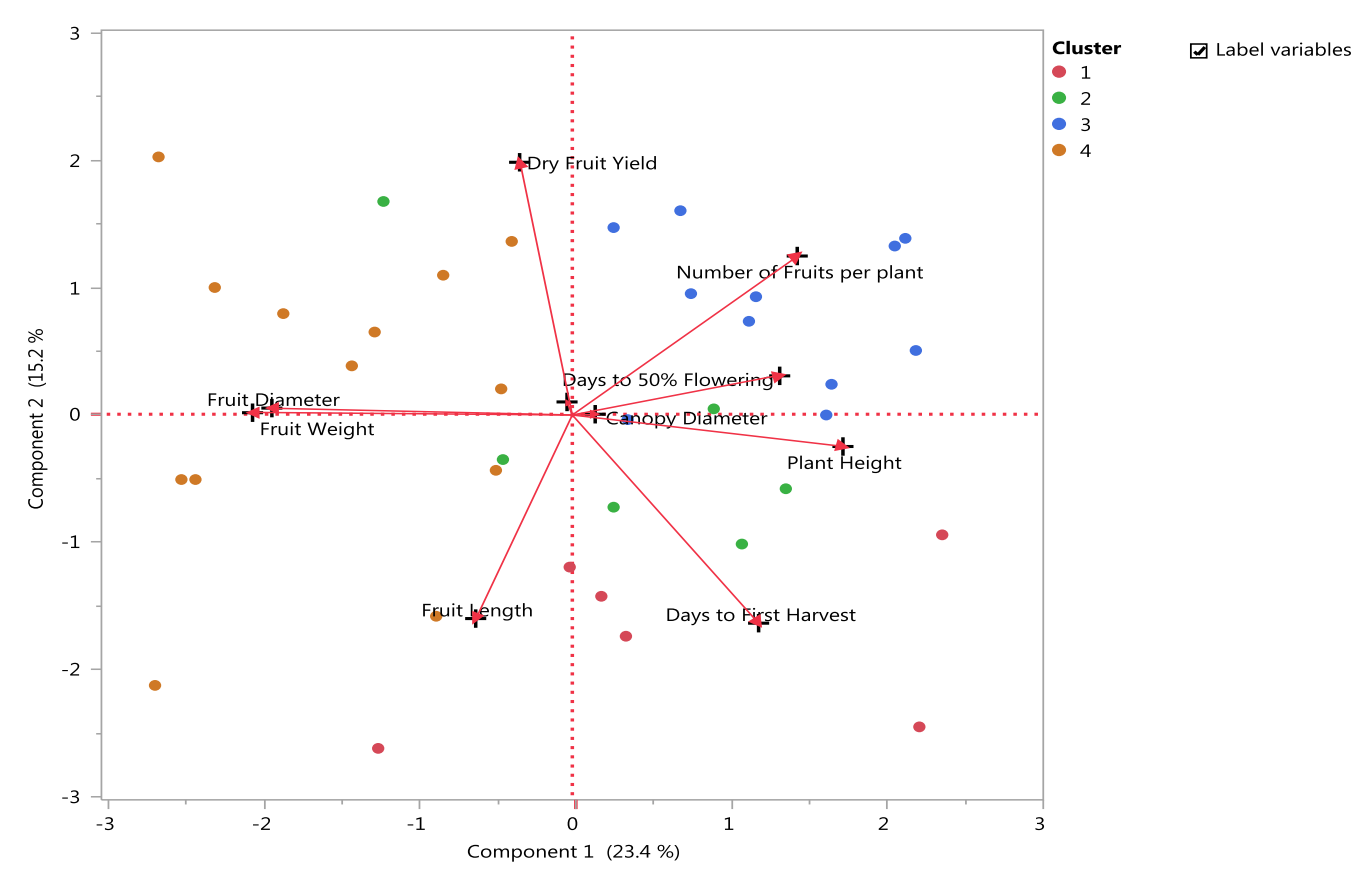

Figure2. Bi-plot showing contribution of 10 traits and distribution of genotypes of hot peppers under Pirn1 and Pirn2

\section{CONCLUSION AND RECOMMENDATION}

\subsection{Conclusion}

Hierarchical complete linkage cluster analysis using Mahalanobis (D2) distance method for 10 quantitative characters grouped the 36 hot pepper genotypes including one check into six clusters. The number of accession per cluster varies in different clusters implies that the prevalence of genetic variation among genotypes for most of the traits under consideration. The maximum intra-cluster distance was observed in cluster I \& III indicated the presence of adequate genetic variability among genotypes within these cluster. The maximum inter-cluster distance was observed between cluster I and II. This result highlighted the possibility of hybrid variety development by using genotypes from distant clusters as parental lines. 
Further, the first five principal components for quantitative traits explained more than half percent of the total variation prevalent within the accessions, out of which the first and second principal components were major contributors. Dry fruit yield per pant, fruit weight, days to first harvest and number of fruits per plant as a whole contributes maximum towards variability regards to Prin 1 and Prin2 in hot peppers genotypes.

Dry fruit yield per plant showed significant and positive correlation with number of fruits per plant and fruit weight both at phenotypic and genotypic levels implies these characters were the major components for hot pepper of dry fruit yield per plant.

Path coefficient analysis based on dry fruits yield per plant as a dependent variable also revealed that number of fruits per plant, canopy diameter, fruit diameter, and fruit weight can be considered as indirect selection index for dry pod yield improvement in hot pepper breeding program.

\subsection{Recommendations}

The analysis results using quantitative traits considered here perceived that some of genotypes appeared distinct and could serve as a genetic source for future breeding program. Thus, genotypes AS75 and AS15 from high dry fruit yielder, AS15 and AS50 from earlier maturity days; AS 52, AS15 and AS75 for hybrid variety development and AS15, AS58-1 and AS104-2 from earlier flowering days may contribute to develop best lines for indicated characters.

\section{REFERENCES}

[1] Ado, S.G., 1990. Pepper Production Guide. Extension Publication Submitted to the Horticultural Crops Research Programme. I. A. R. Samaru, pp: 12.

[2] Berhanu Y; Derbew B; Wosen G and Fekadu M. 2011. Genetic Association Among Some Attribute of Hot Pepper (Capsicum annuum L) Genotypes in West shewa, Ethioppia, Middle East Journal of Scientific Research, 7:563-567.

[3] Berke, T. 2002. Thelvb kl Asian Vegetable Research Development Canter Pepper Project.

[4] Birhanu H, Tiegist D and Yigzaw D.2017. Morphological Characterization of Hot Pepper (Capsicum annuum.L) Land Races of Ethiopia for Qualitative Characters, International Journal of Research Studies in Science, Engineering and Technology, 4 ( 9): 4-9.

[5] Bozokalfa K; Esiyok D.T.K. 2009. Patterns of Phenotypic Variation in A Germplasm Collection of pepper (Capsicum annuumL.) From Turkey, Spanish Journal of Agricultural Research, 7:83-95.

[6] Dale J.W. and Schanz M. 2002.From Genes to Genomes, Concept and Applications of DNA Technology, John Wiley and Sons,Limited.England.360pp.

[7] Habtamu T, Yigzaw D and Wasu M.2014. Effects of Mulching Material on the Early Fruit Yield of Tomato (Lycopersicon esculentum Mill.) Varieties under Polyhouse Growing Condition, Journal of Agricultural Science and Technology, B 4: 612-620

[8] Huffnagel, H.P. 1961. Agriculture in Ethiopia. Food and Agriculture Organization (FAO), Rome, 24, Kaiser, W. J. And R. Hannan, 1987. Seed-treatment fungicides for control of seed borne Ascochyta lentils on lentil. Plant Disease, 71:58-62.

[9] IPGRI (International Plant Genetic Resources Institute). 1996. Descriptors for Capsicum annuum.L. International Plant Genetic Resources Institute, Rome, Italy.

[10] Johnson H.W; Robinson H.F. and Comstock R.E.1955.Estimate of Genetic and Environmental Variability in Soybean.Agro.Journal 47:314-318.

[11] Mahalanobis P.C. 1936. On The Generalized Distance in Statistics.Proc. Nat. Acad. Sci. India. 2:49-55.

[12] Minitab Inc. 1998. MINITAB Reference Manual. Minitab Inc., Pennsylvania. 215p

[13] Nsabiyera V; Ochwo-Ssemakula M and Sseruuwagi P. 2012. Hot Pepper Reaction to Field Deaseas. African Crop Science Journal, 1: 77 - 97.

[14] Occhiuto P.N; PeraltaI. E; Asprelli P.D and Galmarini C.R. 2014. Characterization of Capsicum germplasm collected in Northwestern Argentina based on morphological and quality traits, Agriscientia, 31: 63-73.

[15]Razzaq A; Tariq M.K; Asif S; Sohail K; Alam Z. 2016. Genetic Diversity and Association Analysis for Different Morphological Traits in Capsicum annuum 1. International Journal of Biomolecules and Biomedicine (IJBB), 51: 20-28.

[16] SAS Institute Inc. 2008. Base SAS ® 9.1.3 Procedures Guide, Second Edition, Volumes 1, 2, 3, and 4. Cary, NC: SAS Institute Inc.2355p

[17] SAS Institute Inc. 2013. Using JMP version 13.1, Second Edition, Cary, NC, SAS Institute Inc. 547p 
[18] Shimeles A; Bekele A; Dagne W and Adeferis T/W. 2016. Genetic Variability and Association of Characters of Ethiopian Hot pepper (Capsicum annuam.L) landraces, Journal of Agricultural Sciences, 61: 19-36

[19] Singh R.K. and B.D. Chaudhary. 1996. Biometrical Methods in Quantitative genetic analysis, Kalyani Publishers, New Delhi. 318p.

Citation: Birhanu Habtie \& Tiegist Dejene, "Multivariate Analysis and Traits Association in Hot Pepper (Capsicum annuum) Landraces of Ethiopia." International Journal of Research Studies in Agricultural Sciences (IJRSAS), 2020; 6(10), pp. 42-51, https://doi.org/10.20431/2454-6224.0610005

Copyright: () 2020 Authors. This is an open-access article distributed under the terms of the Creative Commons Attribution License, which permits unrestricted use, distribution, and reproduction in any medium, provided the original author and source are credited. 